Arq. Bras. Med. Vet. Zootec., v.69, n.1, p.101-105, 2017

\title{
Tratamento de um mastocitoma de alto grau na língua de um cão por meio de radioterapia e quimioterapia: relato de caso
}

\author{
[Treatment of a canine high grade lingual mast cell tumor with radiation \\ therapy and chemotherapy: case report] \\ S.C.S. Cunha ${ }^{1}$, K.B. Corgozinho ${ }^{2}$, S. Valga ${ }^{3}$, A.M.R. Ferreira ${ }^{1}$ \\ ${ }^{1}$ Universidade Federal Fluminense - Niterói, RJ \\ ${ }^{2}$ Universidade Federal Rural do Rio de Janeiro - Seropédica, RJ \\ ${ }^{3}$ Médica veterinária autônoma
}

\begin{abstract}
RESUMO
Um canino da raça Boxer, fêmea, de oito anos de idade, foi atendido com salivação, halitose e disfagia. No exame clínico, foi observada uma massa ulcerada no terço médio da língua medindo $3,5 \times 4,0 \mathrm{~cm}$. A histopatologia e a imuno-histoquímica levaram ao diagnóstico de um mastocitoma de alto grau. $\mathrm{O}$ tratamento cirúrgico (glossectomia parcial) foi declinado pelo proprietário, sendo a radioterapia indicada em seu lugar. O protocolo radioterápico empregado foi 15 frações de $300 \mathrm{cGy}$, realizadas cinco vezes por semana. O equipamento utilizado foi de ortovoltagem. A lesão neoplásica apresentou remissão clínica completa a partir da quarta sessão radioterápica. $\mathrm{O}$ único efeito colateral observado foi mucosite leve na região irradiada, que, entretanto, não levou a sintomas clínicos. A quimioterapia sistêmica consistiu de vimblastina e lomustina, alternadas a cada 14 dias, durante quatro meses. Até o momento (22 meses após o tratamento), não há evidências de recidiva local ou metástases do mastocitoma. A associação da radioterapia e da quimioterapia pode ser considerada uma alternativa terapêutica nos casos de mastocitomas irressecáveis, já que, neste caso, levou à remissão completa e duradoura de um tumor agressivo, com ótima tolerância do paciente ao tratamento e posterior qualidade de vida.
\end{abstract}

Palavras-chave: canino, oncologia, radiação, cavidade oral

\begin{abstract}
An 8 year old female boxer was presented with salivation, halitosis and dysphagia. In the clinical examination, an ulcerated mass in the middle third of the tongue was observed, measuring $3.5 \times 4.0 \mathrm{~cm}$. Histopathology and immunohistochemistry the confirmed diagnosis of a high-grade mast cell tumor. Surgical treatment (partial glossectomy) was declined by owner, and radiotherapy was indicated. The protocol consisted of fifteen daily fractions of 300 cGy each. The equipment used was an orthovoltage unit. The tumor had complete clinical remission after the fourth session, and mild mucositis was the only side effect observed. Systemic chemotherapy was performed with vinblastine and lomustine, alternated every 14 days, during four months. There is no evidence of local recurrence or metastasis in this patient twenty-two months after treatment. The combination of radiation therapy and chemotherapy can be considered as an alternative therapy in cases of unresectable mast cell tumors. It led to complete and durable remission of an aggressive tumor, with great quality of life.
\end{abstract}

Keywords: dog, oncology, radiotherapy, oral cavity

\section{INTRODUÇÃO}

As neoplasias de língua em cães são raras, representando apenas $4 \%$ de todos os tumores de orofaringe dos animais (Liptak, 2013). O tumor mais comum nessa região é o carcinoma de células escamosas (Liptak, 2013). Massas acometendo a língua geralmente são dolorosas e interferem na função dela, levando aos sinais clínicos de halitose, ptialismo, anorexia, perda de peso, dificuldade na apreensão, na mastigação e na ingestão de água e alimentos (Liptak, 2013).

Recebido em 31 de março de 2015

Aceito em 6 de julho de 2016

E-mail: simonecsc@gmail.com 


\section{Cunha et al.}

Mastocitomas (MCT) são os tumores cutâneos mais comuns em cães, mas raramente surgem na mucosa oral, incluindo a língua. Essa forma da doença é considerada mais agressiva, tendo altas taxas de metástases regionais e distantes (Elliott, 2014).

Em cães, a ressecção cirúrgica completa deve ser realizada sempre que possível (Patnaik et al., 1984; Liptak, 2013; Elliott et al., 2014). Tumores localizados na porção rostral da língua são detectados precocemente e a intervenção cirúrgica pode ser realizada com amplas margens de segurança. Já quando o tumor atinge a porção caudal da língua, a chance de metástases é maior porque nessa região há um maior número de vasos sanguíneos e linfáticos (Liptak, 2013). A cirurgia é o tratamento de eleição para essas neoplasias, uma vez que os cães toleram bem a glossectomia parcial (Liptak, 2013). Porém, muitos proprietários declinam em fazer a cirurgia devido a questões estéticas e funcionais. A radioterapia é uma opção alternativa nesses casos (Larue e Gordon, 2013).

Este trabalho descreve o caso de um canino diagnosticado com mastocitoma de alto grau na língua e tratado com sucesso por meio de radioterapia e quimioterapia.

\section{CASUÍSTICA}

Um canino da raça Boxer, fêmea, de oito anos de idade, foi atendido com salivação, halitose e disfagia. O proprietário relatou episódios de vômitos e diarreia esporádicos. No exame clínico, foi observada uma massa ulcerada no terço médio da língua, com intensa necrose, medindo 3,5 x 4,0cm (Fig. 1). O animal se apresentava ativo e clinicamente saudável.

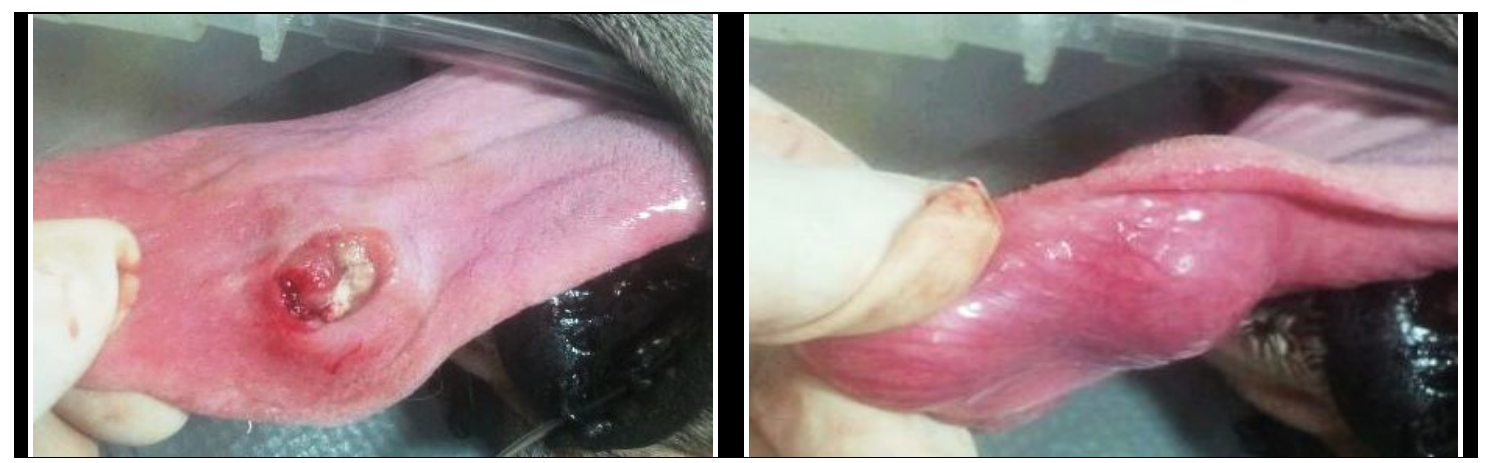

Figura 1. Mastocitoma de alto grau em língua de cão antes do tratamento radioterápico. Observa-se massa ulcerada no terço médio da língua.

Exames hematológicos (incluindo hemograma, ALT, fosfatase alcalina, ureia e creatinina) e de imagem (radiografia torácica e ultrassonografia abdominal) foram realizados. O hemograma revelou apenas monocitose absoluta e a bioquímica se mostrou dentro dos limites da normalidade. Os exames de imagem não revelaram evidências de metástases.

$\mathrm{O}$ animal foi submetido à biópsia incisional da lesão. $\mathrm{O}$ resultado histopatológico revelou intenso infiltrado inflamatório e necrose, com presença de células atípicas arredondadas, com citoplasma eosinofílico, desprovido de grânulos ou pigmentos. As células neoplásicas exibiam núcleos com meganucléolo central e moderado índice mitótico. A conclusão foi de neoplasia de células redondas pouco diferenciada, e um estudo imuno-histoquímico foi sugerido para confirmação do tipo histológico. A imunohistoquímica revelou se tratar de um mastocitoma de alto grau de Kiupel e alta proliferação celular (Ki67 > 23/campo e padrão KIT 2).

O tratamento cirúrgico (glossectomia parcial) associado à quimioterapia sistêmica foi recomendado ao proprietário, que declinou devido ao receio de perda de qualidade de vida do animal. A radioterapia foi proposta para o caso, sendo os possíveis efeitos colaterais decorrentes do tratamento (mucosite) esclarecidos ao proprietário. Em razão das anestesias frequentes necessárias para $\mathrm{o}$ tratamento radioterápico, um ecodoppler e uma eletrocardiografia foram solicitados, apresentando-se dentro dos parâmetros normais. 
O animal foi tratado em uma clínica particular de radioterapia veterinária, com um equipamento de ortovoltagem do modelo Stabilipan I. O planejamento da radioterapia foi realizado em conjunto com o físico médico responsável e teve como base uma tabela de percentual de dose profunda e taxa de dose, que foram previamente estabelecidos com base em testes dosimétricos realizados no equipamento. $\mathrm{O}$ protocolo utilizado foi o de fracionamento padrão (15 frações de 300 cGy realizadas cinco vezes por semana). Para as sessões de radioterapia, o animal foi anestesiado com propofol (Propofol, Biosintética) $4 \mathrm{mg} / \mathrm{kg}$ por via endovenosa. Foram utilizados energia de $120 \mathrm{kV}, 15 \mathrm{~mA}$ e filtro de $2 \mathrm{~mm}$ de alumínio. A distância foco-pele foi de $30 \mathrm{~cm}$, e a taxa de dose foi de $140 \mathrm{cGy} /$ minuto. Para a determinação do campo a ser irradiado, uma margem de cerca de $3 \mathrm{~cm}$ foi dada ao redor do tumor, e lençóis de chumbo de $1 \mathrm{~mm}$ de espessura foram utilizados para proteger as áreas sadias ao redor da lesão.
O acompanhamento do animal foi realizado durante todo o tratamento, e a lesão monitorada quanto à sua evolução por meio de câmeras fotográficas digitais. Os efeitos colaterais do tratamento foram avaliados mediante exame clínico do animal, realizados antes de cada sessão de radioterapia e após 15 a 30 dias após o término do tratamento.

A lesão neoplásica começou a apresentar redução a partir da primeira sessão radioterápica e apresentou remissão clínica completa na quarta sessão (Fig. 2). O canino tolerou bem todo o tratamento radioterápico, não tendo intercorrências no procedimento anestésico e mantendo-se ativo e normofágico por todo o período. $\mathrm{O}$ único efeito colateral observado foi mucosite leve na região irradiada da língua, que teve início na segunda semana de tratamento, mas que não levou a sintomas clínicos.
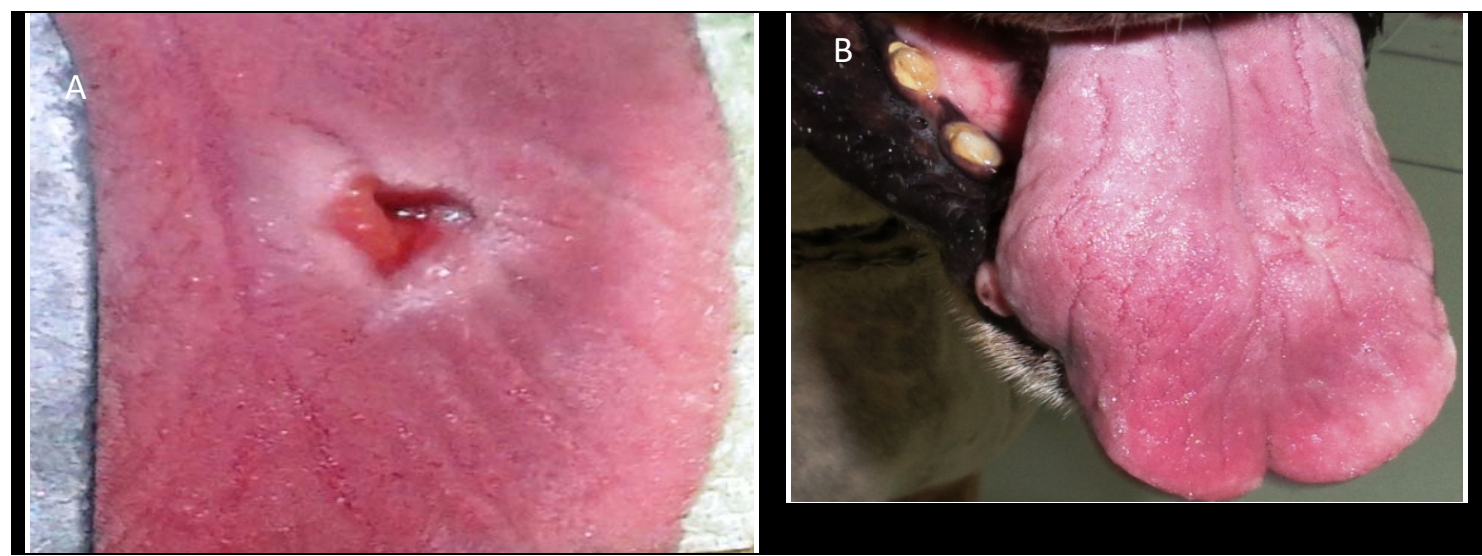

Figura 2. Cão. Remissão da lesão neoplásica durante a quarta sessão radioterápica (A) e após um ano do tratamento (B).

A quimioterapia sistêmica foi iniciada após 15 dias do término da radioterapia, utilizando-se o protocolo Vimblastina/CCNU/Prednisolona. A vimblastina (Velban, Cristal) foi administrada por via endovenosa, na dose de $2 \mathrm{mg} / \mathrm{m}^{2}$, e a lomustina (Citostal, Bristol) por via oral, na dose de $70 \mathrm{mg} / \mathrm{m}^{2}$, alternadas a cada 14 dias durante quatro meses. Antes de cada aplicação, exames de sangue eram realizados para se avaliar a mielosupressão causada pelo tratamento. A prednisolona (Prelone, Aché) foi prescrita na dose de $1 \mathrm{mg} / \mathrm{kg}$, por via oral, a cada 12 horas durante sete dias; após, $1 \mathrm{mg} / \mathrm{kg}$ a cada 24 horas durante sete dias; em seguida, $0,5 \mathrm{mg} / \mathrm{kg}$ a cada
48 horas por mais 14 dias. Ondansetrona (Vonau, Biolab) $0,5 \mathrm{mg} / \mathrm{kg}$ por via oral a cada 12 horas e omeprazol (Omeprazol, Medley) $1 \mathrm{mg} / \mathrm{kg}$ por via oral a cada 24 horas foram administrados durante todo o tratamento para prevenção da náusea induzida pela quimioterapia.

O animal tolerou bem o tratamento, apresentando apenas vômitos esporádicos e leve aumento da atividade das enzimas hepáticas (ALT e fosfatase alcalina), que se mantiveram após o tratamento. Não houve alteração do apetite ou neutropenia durante o tratamento. 


\section{Cunha et al.}

Após o término do tratamento, o acompanhamento oncológico foi realizado a cada quatro meses, por meio de exame clínico, exames de sangue e de imagem. Até o momento (22 meses após o tratamento), não há evidências de recidiva local ou metástases do mastocitoma (Fig. 2).

\section{DISCUSSÃO}

O mastocitoma é uma das neoplasias mais frequentes em caninos. Não há evidência de predisposição sexual e sua incidência aumenta de acordo com a idade, com média dos cães afetados em torno de oito anos e meio. As raças mais acometidas incluem Boxer, Pug, Boston Terrier e Bulldog (Patnaik et al., 1984; FonsecaAlves et al., 2015; Mochizuki et al., 2016). O canino aqui relatado é uma Boxer de oito anos de idade, corroborando a literatura anterior.

A graduação histológica tem sido o método de eleição na tentativa de prever o comportamento biológico do MCT, dividindo os tumores em graus crescentes de malignidade (Patnaik et al., 1984; Kiupel et al., 2011; Sabattini et al., 2015). Essa classificação se baseia no índice mitótico, na quantidade de grânulos citoplasmáticos e no grau de anisocitose (Kiupel et al., 2011; Sabattini et al., 2015). No caso aqui descrito, a histopatologia revelou um tumor extremamente indiferenciado, dificultando até mesmo o diagnóstico histopatológico. A imunohistoquímica teve que ser realizada e revelou um mastocitoma de alto grau de Kiupel. No entanto, o animal não apresentou recidiva ou metástases até o momento, o que sugere que o grau histológico pode não ser preditivo do prognóstico em alguns casos.

O Ki-67 é um fator de proliferação celular e pode ser usado como marcador prognóstico em cães com MCT (Vascellari et al., 2012). Pacientes que apresentam valor de Ki-67 acima de 23 apresentaram menor tempo de sobrevida e maior taxa de recorrência local e de metástase a distância em comparação aos cães com Ki-67 inferior a 23 (Vascellari et al., 2012). A imunomarcação para a proteína c-KIT também pode ser considerada um fator prognóstico importante nos casos de mastocitomas cutâneos caninos (Kiupel et al., 2004). A presença de imunomarcação perimembranosa (padrão c-KIT 1) não está associada à recorrência da doença ou à diminuição da sobrevida, enquanto as marcações citoplasmáticas focais ou difusas da proteína c-KIT (padrão c-KIT 2 e 3, respectivamente) estão associadas ao aumento na taxa de recorrência da doença e à diminuição da sobrevida dos pacientes (Kiupel et al., 2004). Recentemente, um estudo concluiu que cães da raça Boxer com imuno-histoquímica $\mathrm{Ki67+/KIT+} \mathrm{tiveram} \mathrm{menor} \mathrm{sobrevida} \mathrm{em}$ relação aos Ki67-/KIT+ (Fonseca-Alves et al., 2015). A imuno-histoquímica do caso aqui descrito revelou se tratar de um mastocitoma de alta proliferação celular (Ki67 > 23 / campo) e padrão KIT 2, confirmando um tumor altamente agressivo, conforme descrito em MCTs orais anteriores (Elliott et al., 2014). Apesar disso, a taxa de sobrevida foi maior e sem recorrência local por mais de 15 meses.

Massas localizadas na língua geralmente são dolorosas e interferem na função da alimentação, levando aos sinais clínicos de halitose, ptialismo, anorexia, perda de peso, dificuldade na apreensão, na mastigação e na ingestão de água (Liptak, 2013). O canino deste relato apresentava sinais semelhantes, incluindo salivação, halitose e disfagia.

A cirurgia é o tratamento de eleição para essas neoplasias, uma vez que os cães toleram bem a glossectomia parcial (Liptak, 2013). Porém, muitos proprietários declinam da cirurgia devido a questões estéticas e funcionais, como aconteceu neste caso.

A radioterapia tem maior indicação terapêutica como terapia adjuvante após excisão cirúrgica incompleta, porém também pode ser utilizada como terapia única para tumores irressecáveis (Larue e Gordon, 2013). No entanto, os efeitos colaterais ao tratamento radioterápico são um fator de preocupação nessa região, já que podem levar à anorexia e à consequente debilidade do paciente (Colleen e Mayer, 2006). A mucosa oral pode desenvolver reações agudas, que incluem estomatite e glossite, e o dano tecidual máximo ocorre em sete a 14 dias após o tratamento (Colleen e Mayer, 2006; Larue e Gordon, 2013). No presente estudo, o tratamento realizado foi bem tolerado, levando apenas à mucosite leve no campo irradiado, e não levou a sinais clínicos evidentes. 
A quimioterapia deve ser sempre utilizada no tratamento dos mastocitomas de grau III, devido ao seu potencial metastático (Camps-palau et al., 2007; Cooper et al., 2009; Elliott et al., 2014). Também pode ser utilizada em casos irressecáveis, combinada ou não com inibidores de tirosina-quinase (Burton et al., 2015). O protocolo vimblastina/lomustina/prednisolona foi avaliado em um estudo com caninos portadores de MCT graus II e III. Os pacientes foram divididos em dois grupos, de acordo com a presença de doença macroscópica ou microscópica (Cooper et al., 2009). No grupo de doença macroscópica, o tempo livre de doença foi de 210 dias, com sobrevida média de 245 dias. Esses dados são superiores aos descritos em outro trabalho que utilizou o protocolo vimblastina/ciclofosfamida/prednisona, cujo tempo livre de doença foi de 74 dias e sobrevida média foi de 145 dias (Camps-palau et al., 2007). Apesar de, no presente relato, o paciente ter tolerado bem o protocolo quimioterápico instituído, estudos anteriores citam uma taxa de $54 \%$ de toxicidade, embora a gravidade dos efeitos colaterais tenha sido leve (Cooper et al., 2009). Neste relato, o canino apresentou apenas vômitos esporádicos e aumento leve da atividade das enzimas hepáticas, demonstrando que $o$ tratamento foi bem tolerado.

\section{CONCLUSÕES}

A associação da radioterapia e da quimioterapia pode ser considerada uma alternativa terapêutica nos casos de mastocitomas irressecáveis, já que neste caso levou à remissão completa e duradoura de um tumor agressivo, com ótima tolerância do paciente ao tratamento e posterior qualidade de vida.

\section{REFERÊNCIAS}

BURTON, J.H.; VENABLE, R.O.; VAIL, D.M. et al. Pulse-administered toceranib phosphate plus lomustine for treatment of unresectable mast cell tumors in dogs. J. Vet. Intern. Med., v.29, p.10981104, 2015.

CAMPS-PALAU, M.A.; LIEBMAN, N.F.; ELMSLIE, R. et al. Treatment of canine mast cell tumors with vinblastine, cyclophosphamide and prednisolone: 35 cases (1997-2004). Vet. Comp. Oncol., v.5, p.156-167, 2007.
COLLEEN, E.B.; MAYER, M.N. Acute effects of radiation treatment: skin reactions. Can. Vet. J., v.47, p.931-935, 2006.

COOPER, M.; TSAI, X.; BENNETT, P. Combination CCNU and vinblastine chemotherapy for canine mast cell tumours: 57 cases. Vet. Comp. Oncol., v.7, p.196206, 2009

ELLIOTT, J.W.; CRIPPS, P.; BLACKWOOD, L. et al. Canine oral mucosal mast cell tumours. Vet. Comp. Oncol., v.14, p.101-111, 2016.

FONSECA-ALVES, C.E.; BENTO, D.D.; TORRESNETO, R. et al. Ki67/KIT double immunohistochemical staining in cutaneous mast cell tumors from boxer dogs. Res. Vet. Sci., v.102, p.122126, 2015.

KIUPEL, M.; WEBSTER, J.D.; BAILEY, K.L. et al. Proposal of 2-Tier histologic gradind system for canine cutaneous mast cell tumors to more accurately predict biological behavior. Vet. Pathol., v.48, p.147$55,2011$.

KIUPEL, M.; WEBSTER, J.D.; KANEENE, J.B. et al. The use of kit and tryptase expression patterns as prognostic tools for ccanine cutaneous mast cell tumor. Vet. Pathol., v.41, p.371-377, 2004.

LARUE, S.M.; GORDON, I.K. Radiation therapy. In: WITHROW, S.J.; MACEWEN, E.G. Small animal clinical oncology. 5.ed. Philadelphia: Saunders, 2013. cap.12, p.180-197.

LIPTAK, J.; WITHROW, S.J. Cancer of gastrointestinal tract. In: WITHROW, S.J.; MacEWEN, E.G. Small animal clinical oncology. 5.ed. Philadelphia: Saunders, 2013. cap.22, p.381-431.

MOCHIZUKI, H.; MOTSINGER-REIF, A.; BETTINI, C. et al. Association of breed and histopathological grade in canine mast cell tumours. Vet. Comp. Oncol., 2016. (In press).

PATNAIK, A.K.; EHLER, W.J.; MACEWEN, E.G. Canine cutaneous mast cell tumor: morphologic grading and survival time in 83 dogs. Vet. Pathol., v.21, p.469-474, 1984.

SABATTINI, S.; SCARPA, F.; BERLATO, D. et al. Histologic drading of canine mast cell tumor: is 2 better than 3? Vet. Pathol., v.52, p.70-73, 2015.

VASCELLARI, M.; GIANTIN, M.; CAPELLO, K. et al. Expression of Ki67, BCL-2, and COX-2 in canine cutaneous mast cell tumors: association with grading and prognosis. Vet. Pathol., v.50, p.110-121, 2012. 